\title{
Growing biodiversity
}

\section{Your local grocery store shows why variety matters.}

\author{
Farmers' Bounty: Locating \\ Crop Diversity in the \\ Contemporary World \\ by Stephen B. Brush \\ Yale University Press: 2004. 320 pp. \\ $\$ 37.50, £ 25$
}

\section{Stuart Pimm}

Biodiversity's three-part definition - the variety of genes, species and ecosystems is best appreciated on a beach, with tropical forest in front of you, coral reefs behind and mountains in the distance. On rainy midwinter days, in a city far away, there is always the local grocery. Upmarket ones, the habitat of yuppies, make the point; so do rural markets in poor countries. The former sell coffee from 20 countries, plus broccoli, kale, kohlrabi, cabbage and Brussels sprouts, which are all variants of Brassica oleracea. Rural markets in Central America will have variously coloured maize kernels of assorted sizes and types. In Andean valleys you may find a hundred kinds of potato. This is the biodiversity that Farmers' Bounty celebrates. It provides insights into questions of distribution, value and survival that apply to biodiversity as a whole.

Like species diversity, genetic diversity is concentrated in a few regions. These are known as Vavilov centres after a Soviet plant breeder of the 1920s and 1930s who was executed by Stalin for holding inconvenient scientific views. In Farmers' Bounty, Stephen Brush wanders bravely into theoretical ecology to find explanations for how this diversity persists. Agricultural experiences are not widely appreciated by theoreticians, yet they offer important insights. Ecologists debate the generality of the idea that heterogeneous environments promote diversity. Meanwhile, across the world, farmers discuss the advantages of this or that variety in different environments and years as seeds are sorted, and those retained are bought, sold, exchanged and mixed for next season's harvest.

In contrast, uniformity was the norm for potato-growers in Ireland in 1845 and US maize-growers in 1972, and the penalty was devastating. Maize-growers in modern Chiapas in Mexico must contend with risks from summer droughts, strong winds, various soil types and the uncertainties of labour for weeding or applying fertilizer. Growers understand the complexities of the relative advantages in taste, yield and storage of traditional varieties, improved ones and creolized varieties that are the result of decades-long mixing of the two, and decide the proportions of these that they will plant. Simply, crop diversity is the product of a

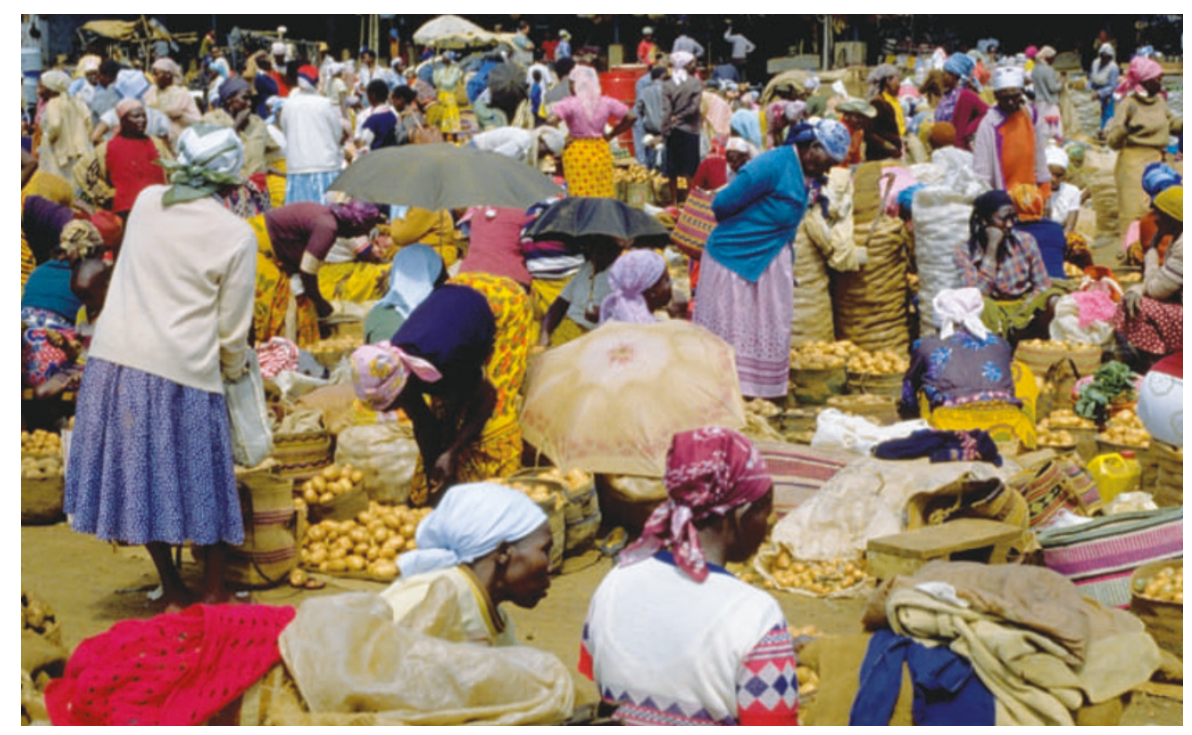

Rich pickings: markets in Kenya have a wide range of potatoes as farmers strive to improve crops.

global annual ecological experiment. It is unregulated and informal, changes constantly as varieties come and go, and is laden with tradition, language and myth. The participants' lives depend on their correctly interpreting the experiment's results.

Modern varieties, with their higher yields, better ability to use fertilizer and resistance to specific diseases or stresses such as drought, have been the major challenge to traditional diversity in the past half-century. 'New' potatoes are now grown in nearly every Andean valley. Governments encourage them, as does the grower's need for a larger surplus. Potato diversity has declined, as might be expected, but traditional potatoes persist, particularly at higher altitudes. They taste better, especially when boiled or baked, and make better gifts, facts not lost on the clientele at my local grocery.

Still, the erosion of variety can be substantial. The Chilean island of Chiloé had some 200 varieties of potatoes in the late 1920s, half that a decade later, and fewer than 40 by 1970 . Brush accepts the general trend and the problems it raises, but his frustration over the lack of global documentation is well taken. The putative features of genetic erosion are that indigenous varieties have limited geographical distributions, they change little from year to year, and their variety decreases as modern varieties, and fertilizer and pesticide use, increase. Studies certainly suggest these outcomes, but often equivocally. Environment, economy and culture often conspire to conserve diversity for reasons that need broader synthesis and assessment.

The familiar solution to retaining diversity is the use of seed banks, such as the
International Rice Research Institute (IRRI) in the Philippines. Brush's view of such collections is that they are necessary but far from sufficient. The heroine botanist of Jurassic Park enthuses over a tree not seen for 65 million years, then gasps as she notices the sauropod eating it. The film imagines extinct species grown from their DNA, but is silent on how to teach dinosaurs which trees to eat. Similarly, seed banks store DNA but lose the complex relationships between the variety, its symbionts and pathogens, and the traditions of the farmers who knew how to plant, tend, harvest and store it. In situ conservation is essential; so is the selection that goes with it. Women in Rwanda select bean varieties, and in Nepal rice and chickpea varieties, that perform better than conventional crop breeders can manage.

If diversity has value, who owns it? In the book's best chapter, Brush discusses the increasing polarity in answers. Fears of 'biopiracy' are widespread in many tropical countries. Stories of how the rich have robbed the poor - and continue to do so influence research-permit applications even for those of us who travel with only notebooks. The Convention on Biological Diversity has a strong theme that plant breeders' rights trump poor farmers' rights. Yet it is often the poorer country that benefits from exchanges - Vietnam gets almost all of its rice from lines developed from IRRI, compared with just a sixth for the United States.

Some countries favour outright protection, such as Ethiopia's ban on the export of coffee plants. Major coffee producers such as Colombia and Costa Rica have a narrow genetic base to their crops; diseases could 
place them at Ethiopia's mercy. Mutual retaliatory actions between these countries would surely cause widespread harm.

Other countries have agreements for bioprospecting, but these bring mixed benefits. It is not always clear, for example, who owns the intellectual property of the varieties. Brush's forceful conclusion is that increasing ownership will abuse the rights of people who have long been involved in the common pool of genetic resources, but who now find themselves excluded by modern patent laws. Stuart Pimm is in the Nicholas School of the Environment and Earth Sciences, Duke

University, Durham, North Carolina 27708, USA.

\section{Myths and men}

\section{Moments of Truth: Four Creators of Modern Medicine}

by Thomas Dormandy

Wiley: 2004. 576 pp. £18.99, \$30

\section{John Galloway}

To misquote Jane Austen shamelessly: "It is a truth not sufficiently universally acknowledged that information is useful only when it provides evidence for or against some view or proposition." The "moments of truth" of Thomas Dormandy's title are the flashes of insight that propelled four nineteenth-century doctors into the medical pantheon. Théophile Laënnec invented the stethoscope; Ignác Semmelweis put an end to childbed fever; Joseph Lister is credited as the founder of antiseptic surgery; and Walter Reed proved that yellow fever was spread by mosquitoes, laying the foundation for its eradication.

The question here is whether Dormandy's book is just a chronicle of the lives of men whose greatness is already a given, or whether it is more analytical and critical, and makes any judgement on the nature and measure of their greatness. Were they justified in taking — or being given — personal credit for a particular breakthrough in medical science? Or were they each just one of several contributors who all deserved some recognition? I think it is fair to say that Moments of Truth has its feet firmly in the first camp. Dormandy says confidently of his four heroes: "They wrote their own papers and books and signed them without equivocation." They were not team players, then.

I enjoyed this book. The life-and-death business of medicine is well-nigh irresistible, as every fan of TV programmes such as ER or Cardiac Arrest knows. The medical background for Laënnec was tuberculosis, which

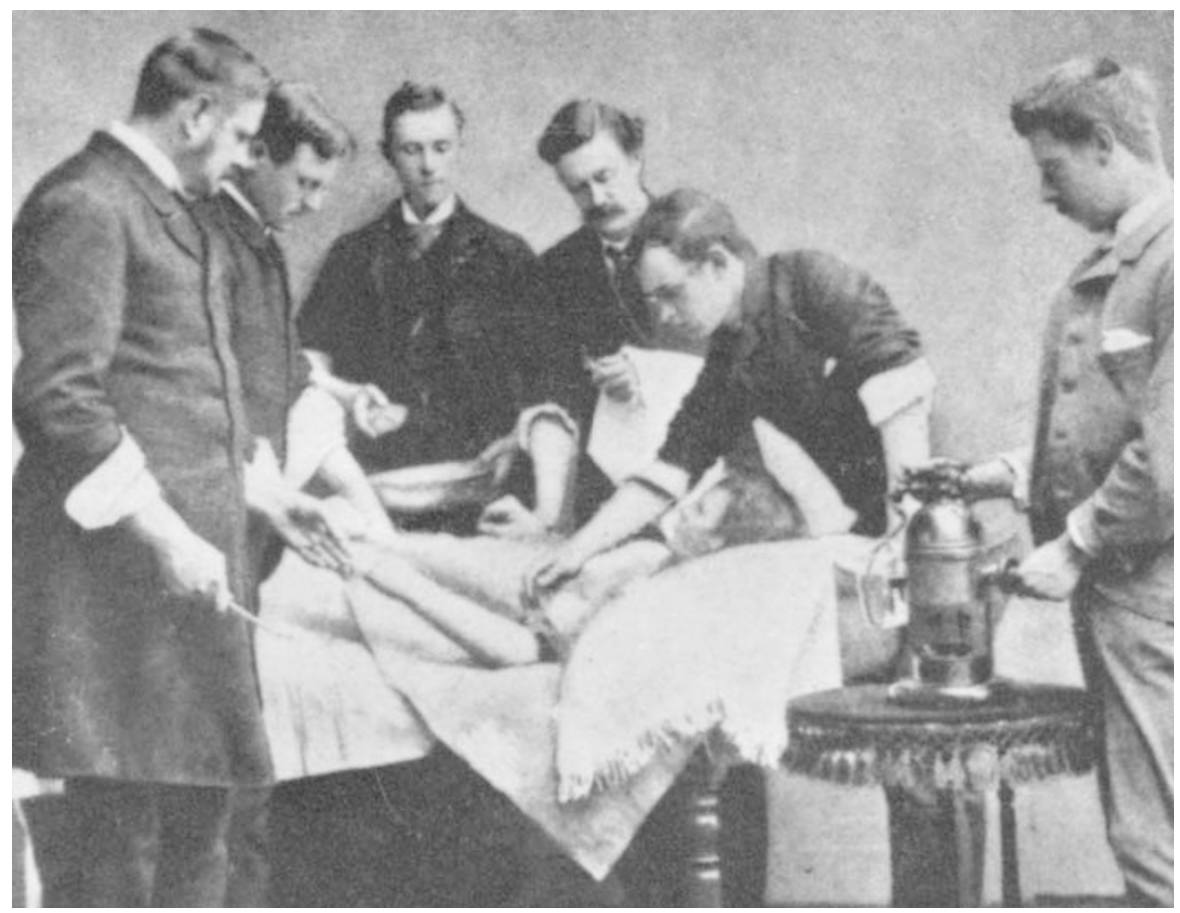

Medical mystery: Théophile Laënnec (below) certainly invented the stethoscope, but how much did Joseph Lister's carbolic acid spray contribute to early antiseptic surgery (above)? killed thousands of people each year in France. Obstetric wards in Vienna, filled with poor pregnant women dying of puerperal fever, were the stamping ground for Semmelweis. Lister's province was the operating theatres of England and Scotland. As the great surgeon James Simpson said: "A patient laid on an operating table in one of our surgical hospitals is exposed to more chances of death than the English soldier on the field of Waterloo." Reed was faced with recurring epidemics of yellow fever among the occupying US troops in Cuba, which killed 20 times as many soldiers as the war. Reed, a military pathologist, headed the commission charged with fighting the disease. For Reed, the larger historical context was crucial in putting him in the right place at the right time, with colleagues who already had a pretty shrewd idea that yellow fever was not directly contagious but spread by mosquitoes - all they lacked was proof.

The stories that Dormandy tells are good, but how do they stand up as history and biography? Novelists, playwrights and journalists recognize one thing above all others: that the essence of drama is that the part (of the hero) is greater than the whole. In real life, however, although individuals do great things, they rarely do them alone. Yet when scientific discovery is presented as drama, it must play down the contribution of others. It is not that they are not mentioned, but rather that they play Rosencrantz and Guildernstern to the great man's Hamlet. We are not given the opportunity to know them as well as we know the central figure. How would the 'moment of truth' look through the lens of the biographies of these minor players, if they were to be written?

Dormandy picks up this point in the book's epilogue but asserts the opposite view, that great discoveries are made only by great individuals, and that no medical scientist illustrates this better than the four men in his book. "Long, long may they flourish," is how he signs off. This presents something of a problem. He decries John Macleod, who shared the Nobel prize with Fred Banting in 1923 for discovering insulin, apparently on the precept that rewarding the unworthy robs the deserving. "He had spent the time of the crucial experiment hunting in the Rockies, unaware that anything interesting was happening in his laboratory." In reality, Charles Best, who worked closely with Banting, was overlooked by the Nobel committee and spent the rest of his life campaigning for recognition. More significantly, arguably the most able member of the team, James Collip, seems to have been written out of the story altogether.

And what about Lister? Was he really the lone genius who ushered in the era of antiseptic surgery single-handedly? Did he then spend 40 years crying in the wilderness, before finally gaining the credit he so richly deserved? Dormandy marshals his facts to give a resounding yes. But some historians think otherwise. They say that the aseptic movement - with its clean wards, bedding 